\title{
English Scholarly Publishing Activities in the Industrial Revolution 4.0: What, Why, and How?
}

\author{
Dedi Turmudi \\ Universitas Negeri Malang, Indonesia \\ tdeditur@gmail.com
}

\begin{abstract}
The presence of the Industrial Revolution (IR) 4.0 has inevitably affected the way how scholars proceed to write. Thus, activities intended to yield a piece of scientific writing facilitated by the obtainability and accessibility of internet browsing is called scholarly publishing. Since English has indisputably become the language of international scholarship and research, it is urgent to have the skill in writing scientific articles benefitting the support from IR 4.0 principles. What is going on with academics and what should they do dealing with the IR 4.0 pertinent to their scholarly writing activities, benefits, and drawbacks. This paper discusses what scholarly publishing in the Industrial Revolution 4.0 and how it supports the process of writing articles for publishing. The purposes of this paper are to explain (1). What are scholarly publishing and industrial revolution? (2). Why is it essential for academics? (3) How does writing scholarly publication in Industrial Revolution 4.0 work? Writing the scholarly publication in English has become obligatory for Teacher-Educator Authors (TEAs) and undergraduate students to doctoral students in Indonesia. The study was a descriptive qualitative library to build a conceptual paper for the purpose of a further study. The method was by reviewing any related kinds of literature to provide sufficient arguments for the three research questions. The outcome is several claims, arguments, and evidence gambits for any author to consider. Theoretically, the IR 4.0 principles have significantly eased the flexibility of the process, the quality, and the credibility of research outputs.
\end{abstract}

Keywords: activities, industrial revolution 4.0, English scholarly publishing, TEAs

How to Cite: Turmudi, D. (2020). English scholarly publishing activities in the industrial revolution 4.0: What, why, and how? English Language Teaching Educational Journal, 3(1), 52-63

\section{INTRODUCTION}

As an Academic language, English has indisputably become the language of international scholarship and research (Flowerdew, 1999). Therefore, writing scholarly publications has become an obligation business for Teacher-Educator Authors (TEAs) and undergraduate students to doctoral students, at least in Indonesia. Every year, around 150.000 students get enrolled, and thus each of them has faced required obligations to publish articles in English before they graduate (Wiryawan, 2014, 2019).

As a result, the minority of them succeeded in publishing; the majority of them managed to find their articles published, and the rest of them had to work very hard to get their manuscripts published. It is not untrue that scientific publishing in developing countries was projected to be a future challenge (Salager-Meyer, 2008). The same problem happened in other countries in China (Zheng \& Guo, 2019), Egypt (Shehata \& Eldakar, 2018), and Poland (Duszak \& Lewkowicz, 2008).

The industrial revolution of 4.0 , on the other hand, is promised to give academicians many benefits to overcome the appearing the challenges. Rajko claimed that IR 4.0 was triggered by the development of Information and Communications Technologies (ICT). "Its technological basis is smart automation of cyber-physical systems (CPS) with decentralized control and the advanced connectivity of the Internet of Things (IoT functionalities)..." (Rojko, 2017, p. 80). 
Why it is worth exploring and how it is applicable in the process of research is the subject of this conceptual paper. Therefore, it is essential to explore more the current tendency of researchers related to the development of an industrial revolution. Also, I found the current work as a redeeming process of mastering academic essays, in which scientific writing is a small part of it (Turmudi, 2017).

Accordingly, this paper is resulted from reviews of related works of literature to answer the following questions; (1) what are scholarly publishing and industrial revolution? (2) why is it essential for academics? (3) how does writing scholarly publication in IR 4.0 work? The objective is to provide theoretical gambits so that readers may have a clear envision when they are faced with writing a piece of scientific writing.

\section{RESEARCH METHOD \\ Data Collection}

The study was a descriptive qualitative library work. It was a literature review to build a conceptual paper. The essences were qualitative data to support the statement arranged in the research objectives, and thus the statistical calculation was not applied (Heigham \& Croker, 2009; Wilson \& Creswell, 1996)

The data were gathered by browsing some articles and books from any journal by the guide of research questions. All were in pdf files and stored in a file of the computer before being uploaded to Mendeley Desktop as secondary data.

For this review or conceptual paper, I did some steps to support the writing process, as described in the following procedure.

1. Using the fixed research questions as the bases keywords to find articles

2. Searching for the target articles using keywords in Google search and certain websites

3. Downloading from the sources in pdf

4. Filing the downloaded articles in my notebook

5. Listing the references using Mendeley Desktop.

All of these steps are to support the further process of data analysis and to secure the references.

\section{Data Analysis}

The needed arguments were gained by reading the related articles in pdf. All data type were qualitative data (Ridder, Miles, Michael Huberman, \& Saldaña, 2014). As all needed articles were selected and filed, I did some steps to support the analysis process.

1. Reading the relevant articles repeatedly based on the research question guideline

2. Citing the supporting arguments based on the topic in-text by paraphrasing the contents or citing directly

3. Listing the sources in the reference list simultaneously

4. Checking the in-text citation and list of references

When all process was completed, I synchronized the research questions and the result and discussion.

\section{FINDINGS AND DISCUSSION \\ What is scholarly publishing?}

Scholarly publishing activity is defined as any activity of studies intended to yield a piece of writing, review, or research for publication, which is also called the scholarly publishing process. In the following, it is beneficial to clarify the various term of the same sense by the author. Further, what is meant by IR 4.0 in the current study? Finally, what are the benefit and the implication for university students are schemed to discuss? 
Given scholarly publishing, I referred to the context of undergraduate students, graduate, and postgraduate students. However; to avoid confusion, I referred the term of scholarly publishing to as described in the table 1 .

Table 1. Sources, Terminology and Meaning

\begin{tabular}{lll}
\hline Sources & Used terminology & Meaning \\
\hline (Flowerdew \& Wang, & "writing articles for & \\
2016) & publication" & Article in English for \\
(Jiang, Borg, \& Borg, & $\begin{array}{l}\text { "writing articles for } \\
\text { publication" }\end{array}$ & publication \\
2015) & $\begin{array}{l}\text { "writing for publication" } \\
\text { (Fazel, 2013), }\end{array}$ & \\
(Salager-Meyer, 2014) & $\begin{array}{l}\text { "scientific publication" } \\
\text { or "scientific articles" }\end{array}$ & \\
"'referred English & \\
(Cheung, 2010), & journals" & \\
(Hyland, 2016), & $\begin{array}{l}\text { "academic publishing" } \\
\text { (Hyland, 2016; Shirey, }\end{array}$ & "scholarly writing “ \\
2013) & "scholarly publishing" \\
(Choi, Choi, \& Kim, & or research aiming at \\
2019; Lei \& Hu, 2019) & $\begin{array}{l}\text { producing a scientific } \\
\text { paper for publication. }\end{array}$ \\
& "in English language" \\
\hline
\end{tabular}

I meant the same thing despite differences in terms. The core sense is any activity to compose scientific manuscript in English for publication.

\section{What is the Industrial Revolution 4.0?}

Industrial revolution 4.0, what is it? The industrial revolution is defined as" the changes in manufacturing and transportation that began with fewer things being made by hand but instead made using machines in larger-scale factories" (www.dictionary.com). Henceforth, IR4.0 is "a strategic initiative recently introduced by the German government aiming at transforming industrial manufacturing through digitalization and exploitation of potentials of new technologies (Rojko, 2017, p. 77).

IR 4.0 is marked by the availability of (1) Internet of Things (IoT), (2) integration of technical process and business, (3) digital mapping and virtualization, (4) smart factory, and smart production (Rojko, 2017, p. 80). In other words, Petrillo claimed: "the current industrial revolution is characterized by the collaboration of intelligent machines, storage systems, and production systems into intelligent networks, merging the real and virtual worlds in cyber-physical systems (CPS)"(Petrillo, Felice, Cioffi, \& Zomparelli, 2018, p. 3). This situation- the availability of IoT-has been inevitably affecting social science and language studies in the sense of finding sources synchronously.

What is the benefit of IR 4.0 for researchers? What does it mean for us as academicians? Any activity of studies intended to yield a piece of scientific writing by reviewing literatures or doing research for publication which is facilitated by the easiness and accessibility of internet browsing is considered as scholarly publishing in the era of 4.0. Its easiness might be affecting significantly on the paradigm of doing studies and the 
process of publishing outcomes simultaneously. Also, it leads to the pathway of being the professionalism of ELT teachers (Afrianto, 2018) by having knowledge management (Roblek, Meško, \& Krapež, 2016).

Further, what is the benefit of 4.0 for researchers? Some studies are reported to have the positive and negative side of 4.0 technology. The benefits are found to be; big accessibility data gained from the sources, the content available online, information sharing, and collaboration synchronously (Roblek et al., 2016). Whereas, the drawbacks are relative to be: alleviating inflexibility, disclosing the secret of data, unsealing copy-right, and borderless ideas.

What is the implication for university students and TEAs? Referring back to the IR 4.0 principles; interconnection; information transparency; decentralized decision; and technical assistant (Afrianto, 2018), it implies that the process of researching with IR 4.0 paradigm involves the essences of (1) the browsing of related articles, (2) clarity of sources and free-plagiarism, (3) autonomous selection of reliable sources, and (4) synchronous peer review, (5) synchronous publication of the studies.

\section{Why is it important?}

Inevitably, the existence of IR 4.0 has facilitated the process, quality, transparency, and accessibility of any ideas the international communities in many ways (Choi et al., 2019). Thus, the following parts are some reasons why it is beneficial.

The first way is by voicing ideas as a contribution to the international academicians. Authors can bring their current research with local sense to the world so that their findings will be a contribution to the global academicians, and thus they are their contribution. The second way is by internationalizing your local context. It may change the local sense of the idea into the general idea substantially. The third way is by integrating the status of the researcher into the knowledge society. Authors are part of the global knowledge society inevitably. Finally, it enables authors to have self-esteeming. As a result, by writing and publishing the piece of your study, it will have an impact on the broader scientist and borderless countries (Board of Editors TEFLIN Journal, 2012). The prior evidence also proves these essential arguments.

Referring to English as the language of scholarly publishing, it has positive sides and drawbacks. Flowerdew has highlighted some helpful things for non-native speakers (henceforth called NNs); such as providing global lingua franca enabling them to communicate with each other across countries in order to share knowledge and becoming other lingua franca in other field and thus, English is no longer a foreign language (Flowerdew, 2015, p. 252).

However; it also has drawbacks for NNs or Non-Anglophone. First, English is the native language of one group of scholars (a minority) and is the additional language for the rest of the global citizen. Whereas, the so-called Anglophone is benefitted since they are freed from any burden to learn the language since they know the tools and the contents. The minority of Anglophone gets benefits economically, academically, and a more significant share in 'paradigm building.' (Flowerdew, 2015, p. 252).

On the other hands, the Non-Anglophone have double burden when associating with scholarly publication in English. They need special effort to master English by investing money to learn English in education sectors. Beyond this, they are pushed to hire tutors or editors unless they acquired the language for written manuscripts. Finally, it may remove the scholars and professionals who do not know the English language with sufficient proficiency(Flowerdew, 2015, p. 252).

Some benefits are also reported by many researchers (Flowerdew, 2015; Hyland, 2016; Rathert \& Okan, 2015). In particular, Rathert \&Okan highlighted the benefits with 
three learning principles: Authorship: capable of creating ideas to be shared, Authority: enable to gain authority as they recognize their expertise, Authorization: projects, networks, or publication authorize teachers to move forward in developing sharing knowledge(Rathert \& Okan, 2015, pp. 364-365).

Further, Flowerdew claimed the negative facets pertaining predominant English language citing Phillipine (1992) and Pennycook (1994) in that English; 1) carries very much ideological baggage ( transmitting ideology);2) devaluating local language and culture;3) perpetuating between native (Ns) and non-native speakers (NNS); 4) publishing in English has benefitted the NS scholars in that writing in English is less challenge compare to that of NNs scholar (Flowerdew, 1999, pp. 244-246).

Other researchers also report paybacks or drawbacks. The positive things are summarized from a published article viewed by certainly experienced authors. It was reported that the benefits cover: 1) a pathway to reach international audiences; 2) a way to communicate ideas with more comprehensive authors; 3)building confidence of intellectual potency; 4) knowing who has been in the scholar areas; 5) learning more from more experienced authors; 6) building international networks; 7) awareness that knowledge is meaningful when it is shared (Board of Editors TEFLIN Journal, 2012, p. 123).

Upon all reviewed sources, we may have a profound glimpse of enriching our schema when writing scholarly publishing so that the benefits of IR 4.0 are inherent in our habit of doing studies.

\section{How does writing scholarly publication in IR 4.0 work?}

Knowing what is scholarly publishing is and what IR 4.0 is the necessary foundation to now know it works. Henceforth, the step is to know how it works simultaneously. Scientific article preparation can be divided into several parts. Gillum and Mendoza have proposed that the manuscript preparation can be divided into three main areas: " 1) planning and conducting the research; 2) analyzing the data; and 3) writing the article (Gillum \& Mendoza, 2014, p. 116). Among the three parts, writing the article is the most challenging one. Therefore, the process is a time-consuming and long-lasting revising process.

Thus, it is difficult to write an article for publication unless certain aspects are mastered. There are eight stages of how an article is written to make it publishable in an individual journal. It is begun from a good idea to publication or novelty. The eight stages cover; "in novel contemplation, in preparation, submitted, in a review, revision-revisedresubmitted, accepted, in- press, publication"(Donovan, 2018, p. 2-5). This proposition needs a technical description to make it clear-cut.

The process to find what attracting topic will be addressed is called "in novel contemplation." While the process to prepare what to write based on the determined novelty is called "in preparation." When the fixed manuscript is sent to a publisher is called "submitted." The process of a manuscript is being judged by a reviewer is called " in a review." After the author has revised the reviewed manuscript and resubmitted to the publisher is called "revision-revised-resubmitted." Last but not least, when the article is stated to be fine for publishing by the journal editor is called "accepted" which is further followed by a process called "in- press." Finally, when the target journal officially publishes the final version of the article is called publication. All of these processes may be slightly different from the latest process of how an article is written with the principle of Industrial Revolution 4.0. 
The characteristics of scholarly publishing in the era of IR 4.0 are marked by the concept of knowledge management (Roblek et al., 2016). The characteristic of the processes is sit up in the following flows

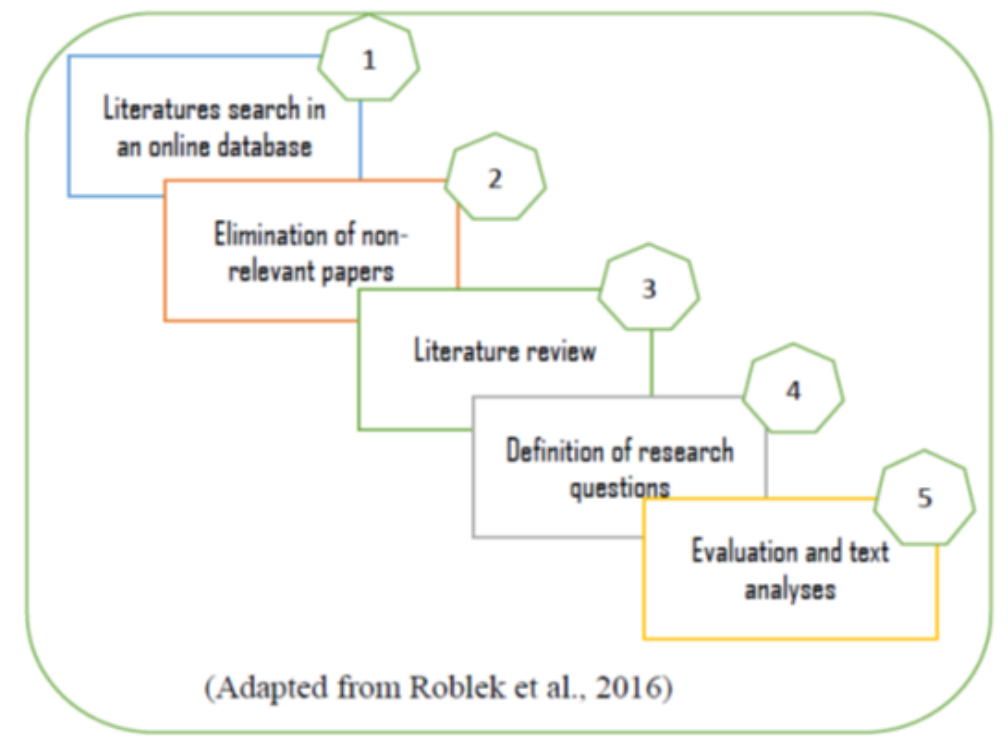

Figure 1. Flow Charts of Initial Writing Scholarly Publication

The flows show that not all aspects are covered by the whole process of writing an article. It looks fine if some options are added to the flows, such as literature management using the software. As for the characteristic of the process, the procedures of researching both old and new paradigms are described in the table 2 .

Table 2. Old Paradigm Versus New Paradigm

\begin{tabular}{|c|c|}
\hline Old paradigm & New paradigm \\
\hline 1. Searching topic in the library & 1. Defining what interest \\
\hline 2. Copying with a different subject or & 2. Searching a topic in internet \\
\hline place & 3. Checking the local context or \\
\hline 3. Searching sources in the library & available research data \\
\hline offline & 4. Redeeming the topic by reading \\
\hline 4. Proposing a research proposal & related articles \\
\hline 5. Doing research & 5. Finding what has not been done \\
\hline 6. Writing the result & (gaps) \\
\hline $\begin{array}{l}\text { 7. Publishing in the library } \\
\text { (asynchronous) }\end{array}$ & $\begin{array}{l}\text { 6. Finding as many as related articles } \\
\text { online }\end{array}$ \\
\hline & $\begin{array}{l}\text { 7. Focusing what will be done } \\
\text { (specification) }\end{array}$ \\
\hline & $\begin{array}{l}\text { 8. Thinking of what impact or } \\
\text { contribution (novelty) }\end{array}$ \\
\hline & 9. Setting up research questions \\
\hline & 10. Writing a research proposal \\
\hline & 11. Doing research \\
\hline & 12. Writing the result \\
\hline & $\begin{array}{l}\text { 13. Publishing openly online (accessible } \\
\text { for everyone) }\end{array}$ \\
\hline
\end{tabular}


The new paradigm takes authors to stages of doing research, pre-during, and postwriting scholarly articles for publication (Turmudi, 2019). Among the many models is the following example. However, it may work for a specific qualitative study only.

Pre-1

1. Setting authors interest

2. Searching related topic synchronously

3. Downloading the selected articles in pdf

4. Consolidating collection in a referencing tool (word reference manager, Mendeley Desktop, Mendeley Cite (free)

5. Reading some trustable, reliable, reputable articles

6. Finding what has been done

7. Identifying what has not been done or what are left out (findings, methods, subjects, sites)

8. Specifying a focus

9. Elaborating what will be impact or contribution to the knowledge

10. Setting objectives of the study

11. Making research questions

Pre-2

1. Creating instruments

2. Validating instruments

3. Writing a draft or outline a research proposal

4. Presenting formally

5. Revising based on feedback

During-1

1. Data gathering

2. Data reduction and coding

3. Data analysis (qualitative)

4. Statistical calculation (quantitative)

During-2

1. Writing the result findings

2. Discussing findings $(1,2,3, \ldots)$; what prior evidences, what current findings, compare both of them, interpret the results, set temporary conclusion $(1,2,3, .$.

3. Concluding findings based on RQ

4. expressing sincere what is not in this research (limitation)

5. Outlining what implications (what should be done or practiced next by educators, researchers

6. Checking component of articles; introduction (previous studies); RQ, Findings, Discussion, Conclusion vs. RQ,

7. Reading, revising, peer review, reading revising, synchronizing in-text and references

Post-1

1. Asking peers to review

2. Self-revising (manual and online)

3. Checking plagiarism-free (online)

4. Submitting to a journal

5. Receiving feedback (online)

6. Revising accordingly 
7. Resubmitting the revised version

(Turmudi, 2019, pp. 1-160)

\section{Referencing tool}

Although the citation system is part of a support system in writing a scholarly publication, it is useful to highlight a vital part of the whole process of doing research. I realized that knowing the skill of using referencing is $25 \%$ of mastering the research itself. Henceforth, it is not wrong to present what type of referencing tools are used by the current researchers. To best of my knowledge and experiences I found some models as listed below;

1. Manual typing system by typing the references;

2. Manual typing system with the format by typing the sources using Word Reference Manager;

3. Manual system by coping reference sources from Scholar Google;

4. Offline automatic system by using Mendeley Desktop

5. Online automatic system by using Mendeley Cite

The description is explained simply in the following table.

Table 3. A Brief Description How Referencing Tool System Works

\begin{tabular}{|c|c|}
\hline Types of the citation system & Short visual illustration \\
\hline $\begin{array}{l}\text { 1. Manual typing system by } \\
\text { typing the references. It is } \\
\text { compatible with any type of } \\
\text { MS Word and Libre Office. }\end{array}$ & $\begin{array}{l}\text { Typing manually; last name, first name, year, title, } \\
\text { city of publication and publisher }\end{array}$ \\
\hline $\begin{array}{l}\text { 2. Manual typing system with } \\
\text { the format by typing the } \\
\text { sources using word } \\
\text { reference manager; it is } \\
\text { compatible with MS Word } \\
2010 \text { or latest. }\end{array}$ & 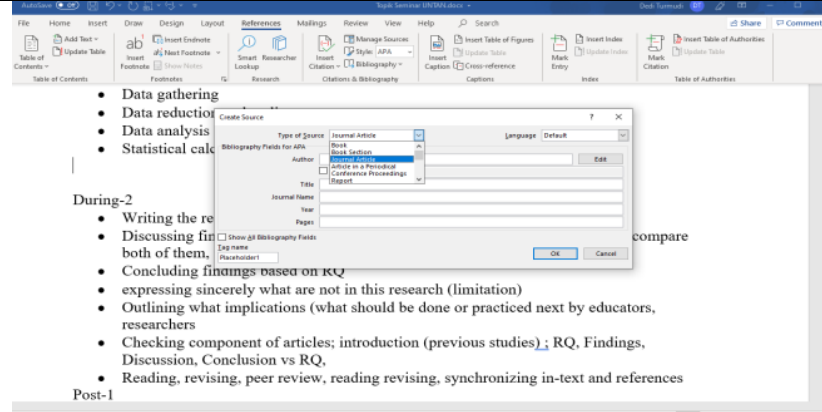 \\
\hline $\begin{array}{l}\text { 3. Manual copying system by } \\
\text { coping reference sources } \\
\text { from Scholar Google; it is } \\
\text { compatible with any type of } \\
\text { MS Word and Libre Office. }\end{array}$ & 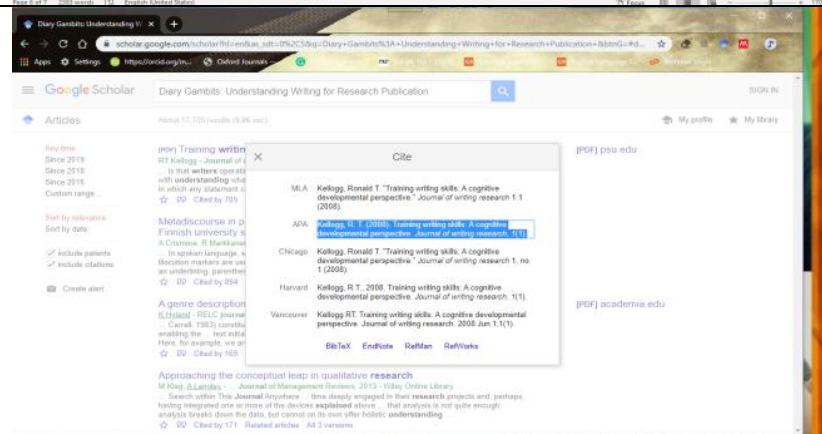 \\
\hline
\end{tabular}




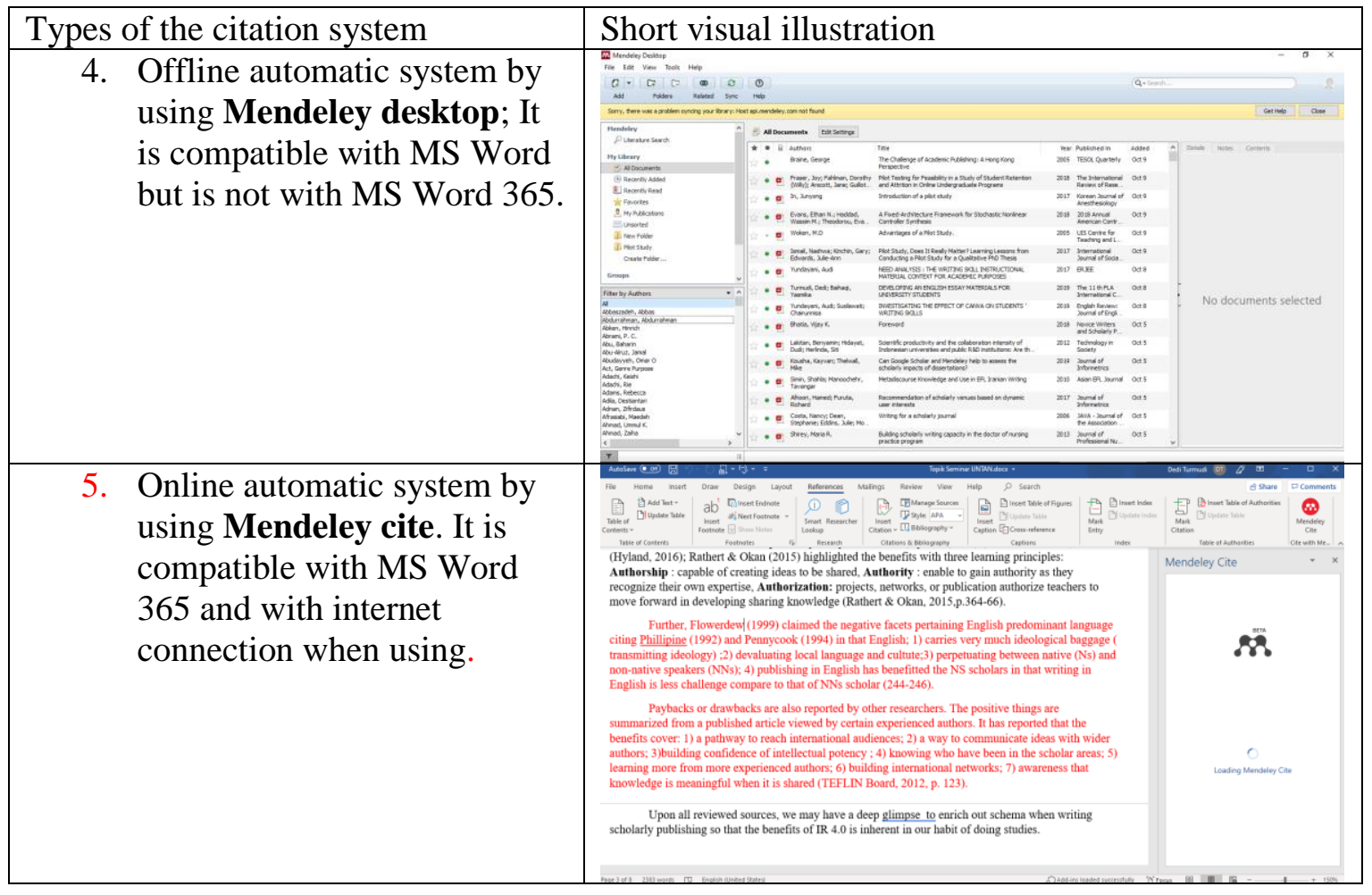

Table 3 shows how authors cite the references from the manual model to the latest model that is a Mendeley Cite. This means that there are still many authors who use one of them. In addition, it is found that all the presented types of referencing tool are still being used by authors of articles. I found this case from reviewing 100 articles published in Volume 1 No 1, 2011 to Volume 8 No 2, 2019 of Premise: Journal of English Education and Applied Linguistics.

\section{LIMITATION}

This study focused on retrieving supporting arguments on why IR 4.0 is essential for Teacher Educator Authors (TEAs) from the internet. The types of articles were various. They were reputable, non-reputable journals, and books. It was found that there was not any restriction on finding the articles to support the proposition of this article. Thus, all were secondary data. Some parts of the essences were taken from a draft of the dissertation by the author of this article. Further study would be recommended to involve some subjects and types of how data were gained. The suggested subjects would be active Teacher-Educator Authors who have techno-alert. The instrument may involve a questionnaire and interview. Thus, a further study on how IR 4.0 affects the current studies comprehensively is needed.

\section{CONCLUSION}

The study focused on three research questions underwriting scholarly publications by knowing what, why, and how IR 4.0. The arguments have shown the academics that the presence of IR 4.0 supports them in writing a research result in many ways. The first one is by providing unlimited, trustable, reputable articles from establishing to established journals. The second one is by providing synchronous feedback from peers, experts, and others. Finally, it is facilitating the availability of online journal publications, enabling 
academics to cite the work efficiently, and thus the citation is an element of impact factor for the authors. These conclusions may be digestible from the extract of theories since the data are secondary. Thus, this paper is limited to conceptual review that may be applicable only for researchers in a qualitative study.

\section{REFERENCES}

Afrianto. (2018). Being a professional teacher in the era of industrial revolution 4 . 0 : opportunities, challenges and strategies for innovative classroom practices. English Language Teaching and Research, 2(1), 1-13.

Board of Editors TEFLIN Journal. (2012). Writing for international publication: An interview with nugrahenny t.zacharias, Handoyo P. Widodo and Willy A.Renandya. TEFLIN Journal, 23(2), 115-129.

Cheung, Y. L. (2010). First publications in refereed English journals: Difficulties, coping strategies, and recommendations for student training. System, 38(1), 134-141. https://doi.org/10.1016/j.system.2009.12.012

Choi, H. W., Choi, Y. J., \& Kim, S. (2019). Compliance of " Principles of transparency and best practice in scholarly publishing " in academic society published journals. Scienceediting, 6(2), 112-121. https://doi.org/10.6087/kcse.171

Donovan, S. K. (2018). Reflective practice: 8 stages of publishing a scientific research paper. Publications, 6(1), 1-5. Retrieved from www.mdpi.com/journal/publication

Duszak, A., \& Lewkowicz, J. (2008). Publishing academic texts in English: A Polish perspective. Journal of English for Academic Purposes, 7(2), 108-120. https://doi.org/10.1016/j.jeap.2008.03.001

Fazel, I. (2013). Writing for journal publication: an overview of NNES challenges and strategies. Journal of Pan-Pacific Association of Applied Linguistics, 17(1), 95-114. Retrieved from http://search.ebscohost.com/login.aspx?direct=true $\& d b=$ eue $\& A N=92595848 \&$ site $=$ eh ost-live

Flowerdew, J. (1999). Writing for scholarly publication in English: The case of Hong Kong. Journal of Second Language Writing, 8(2), 243-264. https://doi.org/10.1016/S10603743(99)80125-8

Flowerdew, J. (2015). Some thoughts on English for research publication purposes (ERPP) and related issues. Language Teaching, 48(2), 250-262. https://doi.org/10.1017/S0261444812000523

Gillum, D., \& Mendoza, I. A. (2014). What is a publishable article? Applied Biosafety, 19(3), 116-117. https://doi.org/10.1177/153567601401900301

Heigham, J., \& Croker, R. A. (2009). Qualitative Research in Applied Linguistics: A Practical Introduction. London: Palgrave Macmillan UK. https://doi.org/10.1057/9780230239517

Hyland, K. (2016). Academic publishing and the myth of linguistic injustice. Journal of Second Language Writing, 31, 58-69. https://doi.org/10.1016/j.jslw.2016.01.005

Lei, J., \& Hu, G. (2019). Doctoral candidates' dual role as student and expert scholarly writer: An activity theory perspective. English for Specific Purposes, 54, 62-74. https://doi.org/10.1016/j.esp.2018.12.003

Petrillo, A., Felice, F. De, Cioffi, R., \& Zomparelli, F. (2018). Fourth industrial revolution: current practices, challenges, and opportunities in Digital Transformation in Smart Manufacturing. InTech. https://doi.org/10.5772/intechopen.72304

Rathert, S., \& Okan, Z. (2015). Writing for publication as a tool in teacher development. ELT Journal, 69(4), 363-372. https://doi.org/10.1093/elt/ccv029

Ridder, H. G., Miles, M. B., Michael Huberman, A., \& Saldaña, J. (2014). Qualitative data 
analysis. A methods sourcebook. Zeitschrift Fur Personalforschung, 28(4), 485-487.

Roblek, V., Meško, M., \& Krapež, A. (2016). A complex view of industry 4.0. SAGE Open, 6(2), 1-11. https://doi.org/10.1177/2158244016653987

Rojko, A. (2017). Industry 4.0 concept: Background and overview. International Journal of Interactive Mobile Technologies (IJIM), 11(5), 77-90. https://doi.org/10.3991/ijim.v11i5.7072

Salager-Meyer, F. (2008). Scientific publishing in developing countries: Challenges for the future. Journal of English for Academic Purposes, 7(2), 121-132. https://doi.org/10.1016/j.jeap.2008.03.009

Salager-Meyer, F. (2014). Writing and publishing in peripheral scholarly journals: How to enhance the global influence of multilingual scholars? Journal of English for Academic Purposes, 13(1), 78-82. https://doi.org/10.1016/j.jeap.2013.11.003

Shehata, A. M. K., \& Eldakar, M. A. M. (2018). Publishing research in the international context: An analysis of Egyptian social sciences scholars' academic writing behaviour. Electronic Library, 36(5), 910-924. https://doi.org/10.1108/EL-01-2017-0005

Shirey, M. R. (2013). Building scholarly writing capacity in the doctor of nursing practice program. Journal of Professional Nursing, 29(3), 137-147. https://doi.org/10.1016/j.profnurs.2012.04.019

Turmudi, D. (2017). Rethinking academic essay writing: Selected genres in comparison. Premise Journal, 6(2), 119-138. https://doi.org/10.24127/pj.v6i2.1052

Turmudi, D. (2019). Diary Gambits : Understanding Writing for Research Publication. (M. F. Yulia, Ed.). Metro, Lampung: CV Laduni AliFatama.

Wilson, R. D., \& Creswell, J. W. (1996). Research design: Qualitative and quantitative $\begin{array}{llll}\text { approaches. Journal of Marketing Research, 33(2), } 252 . & .\end{array}$ https://doi.org/10.2307/3152153

Wiryawan, K. G. (2014). The current status of science journals in Indonesia. Science Editing, 1(2), 71-75. https://doi.org/10.6087/kcse.2014.1.71

Wiryawan, K. G. (2019). Establishment of the Indonesian association of scientific journal editors. Science Editing, 6(2), 148-150. https://doi.org/10.6087/kcse.176

Zheng, Y., \& Guo, X. (2019). Publishing in and about English: challenges and opportunities of Chinese multilingual scholars' language practices in academic publishing. Language Policy, 18(1), 107-130. https://doi.org/10.1007/s10993-018-9464-8 